\title{
Analysis of heart rate variability in pre-eclamptic pregnancy: a study employing frequency domain analysis
}

\author{
Gul Ar Navi Khan ${ }^{1}$, Nazia Ishrat ${ }^{2}$, Zulquarnain ${ }^{2}$ \\ ${ }^{1}$ Department of Physiology, ${ }^{2}$ Department of Obstetrics \& Gynaecology, ${ }^{3}$ MBBS $2{ }^{\text {nd }}$ Year Student, J.N.M.C., AMU, \\ Aligarh, U.P., India
}

Received: 15 October 2014

Accepted: 1 November 2014

\section{*Correspondence:}

Dr. Gul Ar Navi Khan,

E-mail: dr.gular@ rediffmail.com

Copyright: $\odot$ ) the author(s), publisher and licensee Medip Academy. This is an open-access article distributed under the terms of the Creative Commons Attribution Non-Commercial License, which permits unrestricted non-commercial use, distribution, and reproduction in any medium, provided the original work is properly cited.

\section{ABSTRACT}

Background: Preeclampsia is a disorder characterized by development of hypertension to the extent of 140/90 $\mathrm{mmHg}$ or more with proteinuria after $20^{\text {th }}$ weeks of pregnancy in a previously normotensive and non proteinuric woman. Physiologically blood pressure is controlled by Autonomic Nervous System (ANS) so study of ANS during pregnancy plays a significant role to extract some vital information which may be helpful to deal with Pregnancy Induced Hypertension (PIH) or preeclampsia. The autonomic nervous system and changes in ANS during different pathophysiological conditions could be evaluated with heart rate variability analysis test. The modification in the autonomic control occurs during pregnancy and its evaluation through Heart Rate Variability (HRV) analysis is very informative technique now a day but studied little thus the main objective of our project is to compare the maternal HRV changes between normal pregnancy and pre-eclamptic pregnancy.

Methods: 48 subjects (33 of normotensive pregnant women i.e., control group and 15 pre-eclamptic pregnant women i.e, study group) of more than 20 weeks pregnancy were recruited from the outpatients, antenatal unit and wards of obstetrics \& gynaecology department of JNMC, AMU, Aligarh. Physical examination was done and anthropometric measurement like height \& weight were taken. BMI was calculated as per Quetlet's index. Urine test was conducted to every pregnant woman for urine albumin and we designated the pregnant women as pre-eclamptic women on the basis of definition. The subject was advised to take complete bed rest in supine position for 15 minutes in a cool and calm environment. The recording of short term HRV was done according to recommendation of the task force on HRV. The data was transferred from Medicaid machine to window based computer with HRV analysis software. Frequency domain analysis of HRV was taken for further statistical analysis.

Results: There was no significant difference of body mass index was present between them but BMI of pre-eclamptic pregnant women was higher than normotensive pregnant women and it come under obese category $(>25)$. Systolic blood pressure and Mean arterial pressure of study group was significantly higher than control group while diastolic pressure was not significantly higher. All the component of spectral analysis i.e., peak frequency (in $\mathrm{Hz}$ ) and peak frequency (in normalized unit) of pre-eclamptic pregnant women was significantly higher than normotensive pregnant women while in peak power (\%) Low Frequency (LF) \& ratio between LF/HF of peak power was significantly higher than normotensive pregnant women. Others component of peak power (in \%) parameters like VLF \& HF between normotensive and pre-eclamptic women's were non-significant.

Conclusions: The present study clearly indicates that the contribution of anthropometric parameters to the blood pressure changes in pregnancy is negligible between the two groups. Frequency domain analysis showed sympathetic dominance and vagal withdrawal in pre-eclamptic pregnant women. Analysis of sympathetic exaggeration helps us for early detection \& treatment of pre-eclampsia. Study on large sample size and estimation of placental factors (cytokines \& reactive oxygen species) could have been better explained the pathophysiology of preeclampsia.

Keywords: Preeclampsia, Heart rate variability in pregnancy 


\section{INTRODUCTION}

Preeclampsia is a disorder characterized by development of hypertension to the extent of $140 / 90 \mathrm{mmHg}$ or more with proteinuria after $20^{\text {th }}$ weeks of pregnancy in a previously normotensive and non proteinuric woman. ${ }^{1}$ It is one of hypertensive disorders of pregnancy that contributes significantly to still births and neonatal and maternal morbidity and mortality, especially in developing countries of South-East Asia. ${ }^{2}$ In India, pregnancy-induced hypertension (PIH) accounts for about 50000 deaths per year. ${ }^{3}$

Many physiological as well as psychological changes occur in women during their pregnancy. Among the various changes inflammatory, immunologic, hormonal and hemodynamic changes are very important. These changes are influenced by Autonomic Nervous System (ANS). In India abrupt change in life style especially, obesity, hypertension and diabetes have recently been came-up and their adverse effects are responsible for cardiovascular mortality. Physiologically blood pressure is controlled by Autonomic Nervous System (ANS) so study of ANS during pregnancy plays a significant role to extract some vital information which may be helpful to deal with Pregnancy Induced Hypertension (PIH) or Preeclampsia. ${ }^{4}$ The autonomic nervous system and changes in ANS during different pathophysiological conditions could be evaluated with heart rate variability analysis test.

The etiology of PIH is not exactly known but it has been well established that the disease is characterized by low circulating volume and high vascular resistance.,

Usually, two physiological factors that largely contribute to the genesis of hypertension are decreased size of the vascular compartment (vasoconstriction) and increase volume of the compartment (increased blood volume). ${ }^{7}$ However, in this dysfunction, hypertension develops inspite of low blood volume, which clearly indicates that the primary contributor to PIH is intense vasoconstriction induced by sympathetic overreactivity. ${ }^{5}$ The PIH usually develops in the later part of third trimester of pregnancy, in some patients disease manifests early, before completion of $34^{\text {th }}$ week of pregnancy (early-onset PIH), where the disease progresses rapidly. ${ }^{8}$

Scientific researches also revealed that the patients with essential hypertension have faulty noradrenaline reuptake in the cardiac sympathetic nerves which amplify the sympathetic neural signal so the balance between sympathetic and parasympathetic control on cardiac activity can be reflected on the state of heart rate which can be analyzed by Heart Rate Variability (HRV) ${ }^{9-11}$

The terminology HRV indicates the oscillations of the intervals between consecutive heart beats. This phenomenon correlates the autonomic influence on the sinus node. Power spectral analysis of heart rate fluctuations was introduced in 1981 by Akselrod et al. to quantitatively evaluate beat-to-beat cardiovascular control. ${ }^{12}$ Frequency-domain (Power spectral) analysis of Heart Rate Variability's (HRV) is a sophisticated, noninvasive tool for the detection of ANS regulation of the heart. In the field of obstetrics \& gynaecology, HRV is especially suitable for pregnant women because it is virtually non-invasive and produces the least stress on mother and infant.

High HRV is a sign of good adaptation indicating the efficient functioning of ANS. Conversely, low HRV signifies inadequate adaptation of the ANS, indicating physiological malfunction. This HRV analysis can be performed by time domain and frequency domain measures. Time domain measures are the means and standard deviations of R-R intervals obtained by continuous ECG, where NN (normal -to- normal) indicates all R-R intervals.

Spectral analysis of RR intervals provides the frequency domain analysis which separates the heart rate spectrum into a range of components and quantifies autonomic influences on the heart.

The High Frequency (HF) denotes parasympathetic activity (vagal influence) whereas, the Low Frequency (LF) includes both sympathetic and parasympathetic activity

The information obtained from HRV includes: ${ }^{13}$

(a) The Very Low-Frequency (VLF) Power Spectral Density (PSD) components, between $0.0033 \mathrm{~Hz}$ and $0.04 \mathrm{~Hz}$, which are possibly, related to long-term regularity mechanisms (e.g., the rennin angiotensin system, the thermoregularity peripheral blood flow adjustment).

(b) The Low-Frequency (LF) components, between 0.04 $\mathrm{Hz}$ and $0.15 \mathrm{~Hz}$, linked to sympathetic modulation, but also include some parasympathetic influence.

(c) The High-Frequency (HF) components, from 0.15 $\mathrm{Hz}$ to $0.4 \mathrm{~Hz}$, which reflect parasympathetic (vagal) activity.

In the recent years, spectral analysis of Heart Rate Variability (HRV) has been enormously used as a diagnostic tool to assess autonomic functions in different clinical disorders. This also provides a sensitive and early indicator of health impairments. ${ }^{14}$

The role of the autonomic nervous system in preeclampsia is an important area of investigation. The modification in the autonomic control occurs during pregnancy and its evaluation through Heart Rate Variability (HRV) analysis is very informative technique now a day but studied little thus the main objective of our project is to compare the maternal HRV changes between 
normal pregnancy and pre-eclamptic pregnancy. This study will help us to identify the pregnant women prone to develop preeclampsia later during her course of pregnancy so this study could be useful for early detection and treatment of preeclampsia.

\section{METHODS}

The present study was conducted in autonomic lab of department of physiology, JNMC, AMU, Aligarh between the periods of June 2014 to Aug 2014. After obtaining the approval of the project from institutional ethical committee 48 subjects (33 of normotensive pregnant women i.e., control group and 15 pre-eclamptic pregnant women i.e., study group) of more than 20 weeks pregnancy were recruited from the outpatients, antenatal unit and wards of obstetrics \& gynaecology department of JNMC, AMU, Aligarh. Written informed consent was obtained from all pregnant women prior to initiation of the study. All the subjects were explained about the procedure to be undertaken.

Subjects of study group included pregnant women who had risk factors for Pregnancy Induced Hypertension (PIH) so inclusion criteria for the study group included established risk factors for PIH such as family history of preeclampsia, preeclampsia in previous pregnancy, extremes of reproductive age, BMI $>35$, diastolic blood pressure $>80 \mathrm{mmHg}$ at the first visit, underlying medical conditions (diabetes mellitus, renal disease, pre-existing hypertension).

Subjects of control group included pregnant women who had none of above mentioned risk factors for preeclampsia.

All the subjects were examined and detailed personal history was taken with reference to smoking, alcohol ingestion, family history of hypertension, socioeconomic status, rural/urban status etc. Physical examination was done and anthropometric measurement like height \& weight were taken. BMI was calculated as per Quetlet's index. All subjects have to fill proforma. Finally urine test was conducted to every pregnant woman for urine albumin and we designated the pregnant women as preeclamptic women on the basis of definition.

The subject was advised to take complete bed rest in supine position for 15 minutes in a cool and calm environment. During this period subject was advised not to take and perform physical or mental activity. Blood pressure was recorded using mercury sphygmomanometer.

The recording of short term HRV was done according to recommendation of the task force on HRV. Following 10 minutes of supine rest in autonomic laboratory of our department of physiology, all leads of HRV was placed over the subject in requisite position. Lead II of ECG was recorded during supine rest using Medicaid 4 channel system. The data was transferred from Medicaid machine to window based computer with HRV analysis software. Best possible artefact and ectopics were removed. Frequency domain analysis of HRV was taken for further statistical analysis.

\section{RESULTS}

48 subjects (33 of normotensive pregnant women i.e., control group and 15 pre-eclamptic pregnant women i.e., study group) of more than 20 weeks pregnancy were recruited from the outpatients, antenatal unit and wards of obstetrics \& gynaecology department of JNMC, AMU, Aligarh. All pregnant women were underwent Heart Rate Variability test after anthropometric and blood pressure measurement.

Table 1 contained the anthropometric parameters between normotensive and pre-eclamptic pregnant women which showed that both the group were age, height, weight matched i.e., non-significant difference was present between the two groups. Also no significant difference of body mass index was present between them but BMI of pre-eclamptic pregnant women was higher than normotensive pregnant women and it came under obese category $(>25)$.

Table 1: Anthropometric parameters between normotensive and pre-eclamptic pregnant women.

\begin{tabular}{|llll|}
$\begin{array}{l}\text { Anthropometric } \\
\text { measurement }\end{array}$ & $\begin{array}{l}\text { Normotensive } \\
\text { pregnant women } \\
\text { (Control group) } \\
\text { Mean } \pm \text { SD }\end{array}$ & $\begin{array}{l}\text { Pre-eclamptic } \\
\text { pregnant women } \\
\text { (Study group) } \\
\text { Mean } \pm \text { SD }\end{array}$ & $\begin{array}{l}\text { Normotensive vs. } \\
\text { pre-eclamptic }\end{array}$ \\
\hline P value \\
\hline Age (years) & $26.27 \pm 2.10$ & $26.80 \pm 5.81$ & $0.7885 \#$ \\
\hline Weight (meters) & $155.73 \pm 5.10$ & $151.20 \pm 4.38$ & $0.1092 \#$ \\
\hline Weight $(\mathrm{kg})$ & $58.95 \pm 10.79$ & $57.00 \pm 8.216$ & $0.1092 \#$ \\
\hline
\end{tabular}

$* \mathrm{P}<0.05$ statistically significant, \#>0.05 statistically not significant 
Table 2 contained the blood pressure parameters $(\mathrm{mmHg})$ between normotensive and pre-eclamptic pregnant women which showed that systolic blood pressure and mean arterial pressure of study group was significantly higher than control group while diastolic pressure was not significantly higher.

Table 2: Blood pressure (mmHg) parameters between normotensive and pre-eclamptic pregnant women.

\begin{tabular}{|llll|}
$\begin{array}{l}\text { Blood pressure } \\
\text { measurement }\end{array}$ & $\begin{array}{l}\text { Normotensive } \\
\text { pregnant women } \\
\text { (Control group) }\end{array}$ & $\begin{array}{l}\text { Pre-eclamptic } \\
\text { pregnant women } \\
\text { (Study group) }\end{array}$ & $\begin{array}{l}\text { Normotensive vs. } \\
\text { pre-eclamptic }\end{array}$ \\
\hline Systolic BP & $116.55 \pm 15.08$ & $137.20 \pm 5.40$ & P value \\
\hline Diastolic BP & $79.45 \pm 9.55$ & $83.60 \pm 13.74$ & $0.0109^{*}$ \\
\hline Mean arterial pressure & $91.81 \pm 10.88$ & $105.20 \pm 5.576$ & $0.0228^{*}$ \\
\hline
\end{tabular}

*P $<0.05$ statistically significant, \#>0.05 statistically not significant

Urine albumin tests were conducted of every pregnant woman for urine albumin and we designated the pregnant women as pre-eclamptic women on the basis of definition.

Table 3 contained the frequency domain parameters between normotensive and pre-eclamptic pregnant women which showed that all the component of spectral analysis i.e., peak frequency (in $\mathrm{Hz}$ ) and peak frequency (in normalized unit) of pre-eclamptic pregnant women was significantly higher than normotensive pregnant women while in peak power (\%) Low Frequency (LF) \& ratio between $\mathrm{LF} / \mathrm{HF}$ of peak power was significantly higher than normotensive pregnant women. Others component of peak power (in \%) parameters like VLF \& $\mathrm{HF}$ between normotensive and pre-eclamptic women's were non-significant.

Table 3: Frequency domain parameters between normotensive and pre-eclamptic women.

\begin{tabular}{|c|c|c|c|c|}
\hline \multirow{2}{*}{\multicolumn{2}{|c|}{ Spectral analysis }} & $\begin{array}{l}\text { Normotensive } \\
\text { pregnant women } \\
\text { (Control group) }\end{array}$ & $\begin{array}{l}\text { Pre-eclamptic } \\
\text { pregnant women } \\
\text { (Study group) }\end{array}$ & $\begin{array}{l}\text { Normotensive vs. } \\
\text { pre-eclamptic }\end{array}$ \\
\hline & & Mean \pm SD & Mean \pm SD & $P$ value \\
\hline \multirow{3}{*}{ Peak frequency $(\mathrm{Hz})$} & VLF & $0.034 \pm 0.005$ & $0.024 \pm 0.009$ & $0.0152 *$ \\
\hline & $\mathrm{LF}$ & $0.055 \pm 0.02$ & $0.085 \pm 0.03$ & $0.0347 *$ \\
\hline & $\mathrm{HF}$ & $0.179 \pm 0.031$ & $0.148 \pm 0.011$ & $0.0486^{*}$ \\
\hline \multirow{4}{*}{ Peak power $(\%)$} & VLF & $24.04 \pm 14.23$ & $29.56 \pm 29.06$ & $0.613 \#$ \\
\hline & $\mathrm{LF}$ & $53.11 \pm 8.82$ & $64.50 \pm 2.64$ & $0.0146^{*}$ \\
\hline & $\mathrm{HF}$ & $21.02 \pm 8.30$ & $11.94 \pm 7.42$ & $0.055 \#$ \\
\hline & $\mathrm{LF} / \mathrm{HF}$ & $3.168 \pm 2.06$ & $6.832 \pm 4.520$ & $0.0389 *$ \\
\hline \multirow{2}{*}{ Frequency (n.u.) } & LF & $70.18 \pm 7.95$ & $79.82 \pm 6.42$ & $0.0328 *$ \\
\hline & $\mathrm{HF}$ & $28.92 \pm 7.13$ & $20.18 \pm 6.41$ & $0.0348^{*}$ \\
\hline
\end{tabular}

*P $<0.05$ statistically significant, \#>0.05 statistically not significant

\section{DISCUSSION}

In the present study the anthropometric parameters (age, height, weight \& body mass index) of normotensive pregnant women (control group) were matched with preeclamptic pregnant women (study group) and there was no significant difference between the two group but the BMI of pre-eclampsic women was slightly higher than normotensive pregnant women and towards the obese category. In this context few studies suggested that the higher BMI has contribution in autonomic imbalance as increased BMI has been reported to increase sympathetic activity. ${ }^{15}$ The increase in body weight and BMI in pregnancy is mainly due to increase in size of growing fetus, uterus and placenta and increase in ECF volume, not due to increased adiposity ${ }^{16}$ so in our study overall 
contribution of anthropometric parameters to the blood pressure changes in pregnancy is negligible as the corelation between the two group was not significant.

The blood pressure measurement in our study observed that pre-eclamptic pregnant women (study group) have higher systolic and mean arterial blood pressure than normotensive pregnant women which could be due to increased sympathetic tone as few studies defined preeclamptic pregnancy is a state of sympathetic overactivity. ${ }^{5,6}$ The diastolic blood pressure which is an index of peripheral vascular resistance, was also higher in study group but not differ significant with control group. It also reflects the basal sympathetic tone ${ }^{7}$ so sympathetic activation may be the cause of elevated blood pressure in preeclampsia in our study. This observation was supported by the study of H. P. Schobel et al. (1996) and W. Visser et al. (1991).

Frequency domain analysis of heart rate variability in our study showed that there was three component were recorded in spectral analysis i.e., peak frequency $(\mathrm{Hz})$, peak power $(\%)$ and frequency (in normalized units). In all the component Very Low Frequency (VLF), Low Frequency (LF), High Frequency (HF) and the ratio of LF/HF parameter were recorded. The Low Frequency (LF) was significantly higher in pre-eclamptic pregnant women than normotensive pregnant women while High Frequency (HF) was significantly low in pre-eclamptic pregnant women than normotensive pregnant women and also the ratio between the $\mathrm{LF} / \mathrm{HF}$ was significantly higher in pre-eclamptic pregnant women than normotensive pregnant women. Same results were obtained by the study of Cheryl C. H. Yang (2000), P. Shyma et al. (2008), G. K. Pal et al. (2011) and Abdulnasir Hossen (2013).

As we know low frequency component primarily reflects sympathetic modulation of heart functions. ${ }^{14}$ We have recruited the pregnant women of more than 20 week i.e., second trimester. Various spectral analysis studies of HRV depicted that the sympathetic activation occurs mostly in second trimester of pregnancy ${ }^{17}$ which may be exaggerated in case of preeclampsia.

The high frequency HF (n.u.) represents vagal modulation of SA nodal discharge. It was decreased in pre-eclamptic pregnant women (study group) depicting that there was some degree of vagal withdrawal in addition to sympathetic overactivity. ${ }^{14}$

Our study results showed that the increased sympathetic activity was not accompanied by proportionate decrease in vagal tone because $\mathrm{HF}$ of peak power was not significantly decreased in pre-eclamptic pregnant women. Mangala Gowri SR et al. (2013) found the same results and supported our study.

One of the known components of frequency domain analysis, $\mathrm{LH} / \mathrm{HF}$ ratio is the index of sympathovagal balance $^{14}$ which represents the balance between sympathetic \& parasympathetic activities of the individual at any given time in supine resting condition. Lesser value of this ratio indicates parasympathetic dominance and its greater values indicate sympathetic dominance. ${ }^{13}$ In our study LF/HF ratio was significantly high in pre-eclamptic pregnant women in comparison to normotensive pregnant women. As LF/HF ratio reflects increased sympathetic activity so its higher value in study group further confirm the presence of sympathetic overactivity in pre-eclamptic pregnant women. Our results were very much similar to the results obtained by the studies of Cheryl C. H. Yang (2000), Thomas Walther et al. (2005), Abdul Nasir et al. (2013).

It was appeared from various earlier studies that in normal pregnancy from first to last trimester, there is progressive increase in sympathetic activity without so much decrease in parasympathetic activity thus it is suggested that pre-eclamptic pregnancy is a state of exaggeration of the increased sympathetic activity of the normal pregnancy.

Exact cause of occurrence of sympathovagal imbalance in preeclampsia is not known. Recently it was suggested that hypertension in pregnancy is due to release of biologically active circulating factors such as cytokines or reactive oxygen species from placenta(placental factors) that inhibit vascular relaxation pathway or promote vascular smooth muscle contraction. ${ }^{18}$

These placental factor might be acting primarily on medullary cardiovascular centre in the brain to modulate central parasympathetic outflow rather than exclusively acting peripherally o the blood vessel to alter vascular tone as reports indicate that cytokines ${ }^{19,20}$ and reactive oxygen species $^{20,21}$ released peripherally cross bloodbrain barrier and influence activities of various brain centers. Few studies explained that sympathetic overactivity in PIH is not just an exaggeration of sympathetic activation that it usually occurs towards later part of normal pregnancy, ${ }^{22}$ it is an abnormal autonomic reaction that starts in the first trimester with formation of placenta.

\section{ACKNOWLEDGEMENTS}

We are thankful to all the teaching and non-teaching staff members and residents of department of physiology and obstetrics and gynaecology for their support. We are also thankful to our patient to be a part of our study.

Funding: No funding sources

Conflict of interest: None declared

Ethical approval: The study was approved by the institutional ethics committee

\section{REFERENCES}

1. D. C. Dutta. Hypertensive disorders in Pregnancy. In: D. C. Dutta, eds. Text Book of Obstetrics. 7th ed. 
Kolkata, India: New Central book agency; 2011: 219-240.

2. J. P. Greenwood, J. B. Stoker, J. J. Walker, D. A. S. G. Mary. Sympathetic nerve discharge in normal pregnancy and pregnancy-induced hypertension. J Hypertens. 1998;16(5):617-24.

3. P. Gupta, O. P. Ghai. Common complications of pregnancy. In: P. Gupta, O. P. Ghai, eds. Preventive and Social Medicine. 2nd ed. New Delhi, India: CBS Publications; 1998: 358-361.

4. Maria Ireno Rebelo, Jose Manuel, Nieto Villar. Heart rate variability analysis during normal and hypertensive pregnancy: Dissertation of University of Porto, 2010. Available at: http://repositorioaberto.up.pt/bitstream/10216/53927/2/teseeduardo\% 20puente.pdf.

5. H. P. Schobel, T. Fischer, K. Heuszer, H. Geiger, R. E. Schmieder. Preeclampsia: a state of sympathetic overactivity. N Engl J Med. 1996;335(20):1480-5.

6. W. Visser, H. C. S. Wallenburg. Central hemodynamic observations in untreated preeclamptic patients. Hypertension. 1991;17(6):1072-7.

7. W. F. Ganong. Cardiovascular regulatory mechanisms. In: K. E. Barrett, S. Boitano, S. M. Barman, H. L. Brooks, eds. Review of Medical Physiology. 23rd ed. New Delhi, India: Tata McGraw Hill Education Private Limited; 2010: 555568.

8. M. Joydev, L. S. Subroto, B. B. Geeta. Current concepts in PIH. In: G. M. Geeta, eds. Current Obstetrics and Gynaecology, 1st ed. New Delhi, India: Jaypee Publications; 2007: 93-100.

9. Esler M, Rumantir M, Kaye D, Jennings G, Hastings J, Socratous F, et al. Sympathetic nerve biology in essential hypertension. Clin Exp Pharmacol Physiol. 2001;28(12):986-9.

10. Pagani M, Lucini D. Autonomic dysregulation in essential hypertension: insight from heart rate and arterial pressure variability. Auton Neurosci. 2001;90:76-82.

11. Guzzetti S, Piccaluga E, Casati R, Cerutti S, Lombardi F, Pagani M, et al. Sympathetic predominance in essential hypertension: a study employing spectral analysis of heart rate variability. $\mathbf{J}$ Hypertens. 1988;6:711-7.

12. Akselrod S, Gordon D, Ubel FA, Shannon DC, Barger AC, Cohen RJ. Power spectrum analysis of heart rate fluctuation: a quantitative probe of beat to beat cardiovascular control. Science. 1981;213:2202.

13. Task Force of the European Society of Cardiology and the North American Society of Pacing and Electrophysiology. Heart rate variability. Standards of measurement, physiological interpretation, and clinical use. Eur Heart J. 1996;17:354-81.

14. Alberto M. Heart rate variability: from bench to bedside. Europ J Int Med. 2005;16:12-20.

15. N. E. Straznicky, G.W. Lambert, E. A. Lambert. Neuroadrenergic dysfunction in obesity: an overview of the effects of weight loss. Curr Opin Lipidol. 2010;21(1):21-30.

16. F. G. Cunningham, J. L. Kenneth, L. B. Steven, C. H. John, C. G. Larry, D. W. Katherine. Maternal physiology. In: F. G. Cunningham, J. L. Kenneth, L. B. Steven, C. H. John, C. G. Larry, D. W. Katherine, eds. Williams Obstetrics, 22nd ed. New York, NY, USA: McGraw-Hill; 2005: Chapter 5.

17. P. Shyma, G. K. Pal, S. Habeebullah, P. Shyjus, P. Pal. Decreased total power of HRV with increased LF power in early part of pregnancy predicts development $\mathrm{PIH}$ in Indian population. Biomedicine. 2008;28(2):104-7.

18. A. K. Stennett, R. A. Khalil. Neurovascular mechanisms of hypertension in pregnancy. Curr Neurovasc Res. 2006;3(2):131-48.

19. J. D. Johnson, V. Cortez, S. L. Kennedy, T. E. Foley, H. Hanson III, M. Fleshner. Role of central $\beta$ adrenergic receptors in regulating proinflammatory cytokine responses to a peripheral bacterial challenge. Brain Behav Immun. 2008;22(7):1078-86.

20. J. L. Lynch, W. A. Banks. Opiate modulation of IL$1 \alpha$, IL-2, and TNF- $\alpha$ transport across the blood-brain barrier. Brain Behav Immun. 2008;22(7):1096-102.

21. Poulet R, Gentile MT, Vecchione C, Distaso M, Aretini A, Fratta L, et al. Acute hypertension induces oxidative stress in brain tissues. J Cereb Blood Flow Metab. 2006;26(2):253-62.

22. S. Rang, H. Wolf, G. A. V. Montfrans, J. M. Karemaker. Non-invasive assessment of autonomic cardiovascular control in normal human pregnancy and pregnancy-associated hypertensive disorders: a review. J Hypertens. 2002;20(11):2111-9.

DOI: $10.5455 / 2320-1770 . i j r \operatorname{cog} 20141232$

Cite this article as: Navi Khan GN, Ishrat N, Zulquarnain. Analysis of heart rate variability in preeclamptic pregnancy: a study employing frequency domain analysis. Int J Reprod Contracept Obstet Gynecol 2014;3:1037-42. 